\title{
Mergers and Acquisitions: A Qualitative Study in the Medical Device Sector
}

\author{
${ }^{*}$ Alon Ben Jacob ${ }^{1}$ \\ 'Vialden Iniversitỵ, Ninneiapolis, Ninnessoti, ISI

\begin{abstract}
One of the key processes that business leaders are using to grow their organizations is mergers and acquisitions (M\&A). As such, the M\&As are considered as a critical process with considerable implications for the company's profitability and growth. Still, between 70 to 90 percent of the M\&As deals fail to deliver the expected value to the acquirers. The purpose of this qualitative study was to explore strategies that industry leaders used to conduct successful M\&A processes. The conceptual framework of this study is based on Sarasvathy's effectuation theory. Eight face-to-face interviews were conducted with participants from a global healthcare company who acted as the company's presidents or executives and had experience conducting M\&As. The data were coded, and themes were emerged using Microsoft office and NVivo 10 software. Six themes were emerged through data analysis: leadership focus, value creation, integration strategy, the review process, relationship development, and organizational governance. The results of this study could be used to improve leadership strategies when conducting the process of M\&A. The implications for positive social change might enhance the stability of the healthcare industry and the individuals who consume healthcare products. Also, this will bring to improved
\end{abstract} \\ health outcomes, well-being, longevity, and quality of life. \\ Keywords: Mergers, acquisitions, effectuation theory, \\ entrepreneur, integration, inorganic growth, new \\ product development \\ JEL: G30, G32, G34
}

Business leaders are continually looking for ways to grow their business in terms of size, market share, product line, and profitability (Farhan, Aneeta and Shafique, 2018). Some leaders use organic growth and rely on internal resources and capabilities that exist within their companies for product development. Some business leaders adopt inorganic growth strategy mainly by using M\&As of companies having skills that can complete missing capability or market. Also, in using M\&As, business leaders have the opportunity to quickly develop new markets or seeking the transfer of technology and innovation to keep pace with the globalization of business (Bauer, Matzler and Wolf, 2016).

In recent years there is an increasing trend of large organizations that have been actively engaged in M\&A activities to pursue business growth (Sinclair and Keller, 2017). Still, the majority of M\&As fail to deliver the expected value to the acquirers ( $\mathrm{Du}$ and Jaw, 2018). The increasing trend in M\&As transactions all over the world (Loukianova, Nikulin and Vedernikov, 2017) brought to the need to identify ways to improve the success rate of M\&As.

Little research has been conducted to explore why the majority of M\&A failed, and there was no 
conclusion or direction on how to improve the success rate using strategies that proved to be successful. Business leaders need to make decisions while they face uncertain situations during the $M \& A$ process. In the literature of entrepreneurship, the effectuation theory has been applied widely as a tool to investigate decision-making and its logic. The effectuation theory used in the study was the first time that entrepreneurial decision-making theory is evaluated with regards to the M\&A process. This research suggested strategies that successfully used in the past and guide how to use those strategies along with the effectuation theory concepts in a manner that can Improve the M\&A success rate. The improvement of M\&A transactions is essential to foster the stability of the industry, the creation of more job opportunities, and the acceleration of new technologies through innovation and introduction of new products.

As little research was conducted to explore the reason for M\&A failures, it was important to evaluate this further. The purpose of this qualitative single-case study is to suggest ways to identify and explore the strategies business leaders used to conduct successful M\&As. Therefore, the central research question for this study is: What strategies do business leaders use to conduct successful M\&A processes?

The population for this study consists of eight business leaders from a global leading healthcare company who have been successful in executing M\&As. The effectuation theory is used to develop the conceptual framework for this research, and to identify and explore the strategies that key business leaders use when they face an uncertain situation. As the M\&A process has multiple uncertainties, the usage of the effectuation theory led to concepts that correlate with the six themes emerged through data analysis.

The next section in this article i.e., literature review explains the M\&A process, the factors that impact $M \& A$, and the evaluation of the effectuation theory that is applied to develop the conceptual framework for this study. The methodology section explains the qualitative single-case study design and some of the challenges. As part of the data analysis, common themes that emerged from the interviews are identified. As this study uses the qualitative method, the participants' experience and understanding of the phenomenon are used to base the study findings as presented in the discussion section. Finally, implications, limitations and future directions, and recommendations are reported.

\section{LITERATURE REVIEW}

Researchers characterized mergers as a combination of two organizations into a new single organization (Haeruddin, 2017). As illustrated in Table 1, there is extended literature available dealing with the M\&A process (Bari, Fanchen and Baloch, 2016; Bhagwan, Grobbelaar and Bam, 2018; Sincl- 


\section{Ben Jacob}

air and Keller, 2017). Also, the literature covers the M\&A outcomes (Eckardt and Skaggs, 2018; Feng, 2016; Junni et al., 2015), and the variables and factors that could have influenced the M\&A outcome (Daniliuc, Bilson and Shailer, 2014; Friedman et al., 2016; Hongjiu, Qingyang and Yanrong, 2019; Kar and Kar, 2017; Nandi and Nandi, 2017).

\begin{tabular}{|c|c|}
\hline Author(s) & Major Findings \\
\hline Eckardt and Skaggs (2018) & $\begin{array}{l}\text { M\&A results in the earning of a complete product and immediate access } \\
\text { to new clients. }\end{array}$ \\
\hline El Zuhairy (2015) & M\&A success factors and key success indicators. \\
\hline Fine, Gleason and Budeva (2016) & $\begin{array}{l}\text { Relationship creation as a factor that contributed to the success of the } \\
\text { M\&A process. }\end{array}$ \\
\hline Sinclair and Keller (2017) & M\&A activity as a way to pursue fast business growth. \\
\hline Daniliuc, Bilson, and Shailer (2014) & $\begin{array}{l}\text { The influence of the acquisition and integration management processes } \\
\text { on the long-run post-acquisition performance. }\end{array}$ \\
\hline Ahmed (2019) & $\begin{array}{l}\text { Effective leadership support active collaboration, commitment, and can } \\
\text { improve M\&A outcomes. }\end{array}$ \\
\hline Kar and Kar (2017) & Cross-cultural factors impact on M\&A outcomes. \\
\hline $\begin{array}{l}\text { Rottig, Schappert, and Starkman } \\
\text { (2017) }\end{array}$ & $\begin{array}{l}\text { The acquisition process, the national culture, and the organizational } \\
\text { culture are factors that impact M\&A. }\end{array}$ \\
\hline Friedman et al. (2016) & Communication as a factor that can improve M\&A performance. \\
\hline Nandi and Nandi (2017) & $\begin{array}{l}\text { Strong leadership combined with effective communication can promote } \\
\text { employees' motivation and support the success of the integration efforts. }\end{array}$ \\
\hline Bari, Fanchen, and Baloch (2016) & M\&A process and strategies. \\
\hline $\begin{array}{l}\text { Bhagwan, Grobbelaar and Bam } \\
\text { (2018) }\end{array}$ & The process steps of the M\&A deal. \\
\hline Eckardt and Skaggs (2018) & $\begin{array}{l}\text { M\&A expected outputs in terms of new products and immediate access } \\
\text { to new clients. }\end{array}$ \\
\hline Feng (2016) & M\&A financial aspects. \\
\hline Junni et al. (2015) & Factors that can influence the outcome of M\&A. \\
\hline $\begin{array}{l}\text { Hongjiu, Qingyang, and Yanrong } \\
\text { (2019) }\end{array}$ & Uncertainty and risk as part of the M\&A process. \\
\hline
\end{tabular}

Source: Author's Presentation

\section{Table 1. Major Findings of Studies Included in Literature Review}

In the last decade, there is an increasing trend of company leaders who seek ways and methods to improve their company performance and company results. One way to improve company performance is by investing via the internal company's resources in innovation and new product development (NPD). This method of using the internal company resources called organic growth, and the advantages of using this method are better control on project timeline, deliverables, resource as this is controlled by the company personnel according to the company procedures. Another way to improve company performance and growth is by investing outside of the company by executing M\&As. The use of inorganic growth methods, such as M\&A, provides companies immediate access to new clients, and as such, this can be a quick way to achieve new client relations and projects needed for revenue growth (Eckardt and Skaggs, 2018). When companies are using the inorganic path, the time 
to market is fast and can benefit immediate actions and profits to the acquired company.

Although both terms of merger and acquisition are often expressed in the same breath and used as though they were synonymous, the terms merger and acquisition mean slightly different things (El Zuhairy, 2015). A keynoted difference is related to how the purchase is communicated to and received by the target organization's board of directors, employees, and shareholders (El Zuhairy, 2015). Still, business leaders continue to use M\&A as a popular form of improving market capabilities, channel relationship strength, and generate value to their brand portfolio (Fine, Gleason and Budeva, 2016).

Large organizations have been actively engaged in M\&A activity to pursue business growth (Sinclair and Keller, 2017). Some factors can contribute to the successful outcome of M\&A transactions. Leadership focus is the ability of business leaders to accurately define their business goals and drive their team to execute these goals. Daniliuc et al. (2014) reported that the critical role and effect of leadership focus during the acquisition process have a significant impact on the performance and financial results of the post-acquisition. According to Ahmed (2019) team leadership is critical in creating an environment where the staff understands the importance of working across interdisciplinary groups, ensuring a high level of trust, reduce stress, increased job satisfaction, strengthening of relationships, and fostering of ownership.

The cultural impact is an additional factor that may impact M\&A performance. The research literature on M\&As has attributed the failure of deals primarily to cross-cultural factors (Kar and Kar, 2017). Rottig, Schappert and Starkman (2017) suggested that major success factors are the acquisition process, the national culture, and the organizational culture and practices. The challenge of an external company that has its own culture to integrate into the acquired company is high. Besides integration difficulties, culture is an element that adds more complexities.

Friedman et al. (2016) also noted in their study that researchers reveal that many of the M\&A deals produce a negative return to the acquired company. Friedman et al. (2016) examined the potential sources of failure and success of M\&A and found that communication plays a vital role that can improve M\&A performance. Nandi and Nandi (2017) evaluated the social side of M\&A and the impact of it on the employees and their identification with their former firm. According to Nandi and Nandi (2017), strong leadership combined with effective communication can promote employees' motivation and support the success of the integration efforts.

Another factor that contributes to the evaluation of M\&A performance is the financial aspect. The need to measure the outcome of M\&A activity is essential to assess the contribution of this activity to the company performance. Measuring financial results is one of the tools that researchers and business leaders use to evaluate company performance. As such, there is a strong connection between the financial measurements and the conclusion of the M\&A. 


\section{Ben Jacob}

\section{Conceptual Framework}

Researchers use entrepreneurship research to study the identification, evaluation, and exploitation of opportunities by entrepreneurs (Yang and Gabrielsson, 2018). Entrepreneurs are individuals who discover, evaluate, and exploit opportunities (Yang and Gabrielsson, 2018). Entrepreneurial activity exists in multiple industries and fields, and the outcomes of such activity usually result in a new process, product, or opportunity for something new that did not exist before. The ability of entrepreneurs to use structured tools and guidance to support them during this process that includes multiple uncertainties may allow them to achieve better results.

Sarasvathy introduced the effectuation theory in 2001 as a tool for decision-making logic in entrepreneurship environments that tend to have multiple uncertainties (Reymen et al., 2017). Sarasvathy sought to identify and understand the teachable and learnable elements of entrepreneurial expertise (Sarasvathy et al., 2014). Sarasvathy and Dew (2005) suggested the following five principles for effectuation: means, design, partnership, affordable loss, and leverage contingency. The five principles and the overall logic of effectuation have since being named as follows: bird-in-hand, affordable loss, crazy quilt, lemonade, and pilot-in-the-plane. The bird-in-hand principle referred to the entrepreneurs needs to be open to new possibilities, rely on their capabilities, and use their social interaction as a mean to guide their activities and decisions. When pursuing M\&A opportunities, business leaders explore options without knowing the potential impact; hence they need guidance similar to the bird-in-hand principle to support their activities. The affordable loss principle referred to the planning process that entrepreneurs do that takes into account the possibility of failure and reduce the planning time. This principle guides the risk-taking process in focusing on the loss the entrepreneurs can afford. When using this principle in the M\&A activities, the business leaders can use it as a guide to plan their strategy during the M\&A transactions. The crazy quilt principle referred to the action that entrepreneurs do to engage with stakeholders to create a potential partnership, and this applies to the M\&A activity when the teams from the target and the acquiring company develop relations and trust to support the M\&A activity. The lemonade principle related to the approach of leveraging uncertainty by treating surprises as opportunities. As the M\&A process includes a lot of changes, it is beneficial to use the lemonade principle as part of planning the M\&A process to be able to be better prepared. Lastly, the pilot-in-the-plane principle referred to the activities that entrepreneurs do to transform and reshape the area that they are acting. This principle applies to the M\&A outcome that is planned to bring to the acquiring company more revenues, customers, and new markets.

Each principle corresponds to a particular approach to problem-solving related to personal inspiration, not to prediction (Jisr and Maamari, 2017). According to Sarasvathy (2001), leaders deal 
with uncertainty by adopting a more flexible approach and investing only noncritical amounts of resources into opportunities, while seeking feedback early in the process through stakeholder interactions. The ability to enhance the robust process in an uncertain environment allows for a decision-making process that involves experimentation and learning (Reymen et al., 2017).

The effectuation theory is selected as the conceptual framework for present study. Business leaders act in an uncertain environment and need to evaluate and base their decisions on the available information. In the process related to $M \& A$, there are multiple elements that business leaders need to assess before deciding if to proceed with this transaction. The principles of the effectuation theory identify the tools that key business leaders use when they face an uncertain situation such as an M\&A. The ability to examine strategies that leaders use successfully to conduct M\&As may support business leaders' decisions and strategies for executing a successful M\&A.

\section{METHODOLOGY}

Before conducting a new social science study, a researcher needs to consider and choose a research method (Yin, 2018). The qualitative methodology was selected for this study because this approach is applicable to explore a specific and complex phenomenon within its real-world context (Yin, 2015). A qualitative study was conducted to identify and explore business leaders' strategies to perform successful M\&A processes. In qualitative studies, interview questions are considered to be the research instrument (see Appendix-I). The interview questions were designed to gather information to answer the research question (see Lewis, 2015). The reliability of this study was achieved by using consistency in data collection, organization, and analysis methods throughout the research. Each interview was conducted using an interview protocol, transcription, initial summary that included the interpretations developed from the interview responses, and a member-checking with the participants to enhance the dependability of results. According to Lub (2015) since the researchers talk to people and observe them up close, they need to have tact and sensitivity to capture accurate information. Member checking was used to improve the credibility of data analysis.

A qualitative single case-study design was used to identify and explore business leaders' strategies used to conduct successful M\&A processes. The single case study design was chosen as it best fits the structure of this study. The medical industry was selected as this industry is active and requires state of the art products and services to meet the continuous demand of the population needed healthcare solutions. The target sample chosen for this study consisted of eight business leaders from a global leading healthcare company that have been successful in executing M\&As. The participants made a proper sample and allowed reaching data saturation. 


\section{Ben Jacob}

The challenge in this study was to identify a suitable organization that can represent extended M\&A activity. In addition to that, this organization should have business leaders who had succeeded in executing an M\&A and who would be willing to participate in the interview process and share their perspective on the factors that contributed to this success (see Yin, 2015). The participants that were identified were key business leaders serving in a US based leading global healthcare organization. This global healthcare organization has several companies, and the participants were acting as presidents or executives in those companies and routinely conducted M\&As. Those business leaders used M\&A to benefit their company with different cultural values and to share the control of a joint entity with another owner (see Farhan et al., 2018).

Interviews are the primary data source in many qualitative studies (Yin, 2018) and allow the researcher to interact with the participants at a personal level. As such, the researcher needs to be fully present while engaging with the narratives and stories that the interviewee shares with them (Karagiozis, 2018). Semi-structured interviews were the data collection method used in this study as per Yin (2018) the interview is one of the most important sources of case study evidence. The participants were asked to answer seven questions (see Appendix-I) and were audio-recorded. The interview questions were developed to enable accurate data collection and sensitivity in capturing the data correctly to enable reliability and validity (Jacob, 2020). Also, handwritten notes were taken and were used to transcribe and create a summary of the interview responses. The summary described the interpretations developed from the interview responses, and this was sent to each participant for review and comments. The member checking was conducted with each participant to review the interpretation and to confirm it is accurate.

Upon receiving feedback from participants and confirmation that they agreed with the researcher's interpretations, the data were manually entered into Microsoft Word and Microsoft Excel for the starting of the first coding analysis. Key themes were coded based on the similarity of words, concepts, and occurrences. The transcribed data were entered into NVivo to verify that the frequency of themes that were analyzed manually was the same as the frequency of the theme that resulted from the usage of the NVivo software.

\section{RESULTS}

Data analysis was performed using the data collected from the semi-structured interviews. The participants in the study were key business leaders with executive roles, as illustrated in Figure 1. The participants took active roles in many M\&A deals, as shown in Figure 2.

Based on the analysis, six primary themes that business leaders used to conduct successful M\&A 


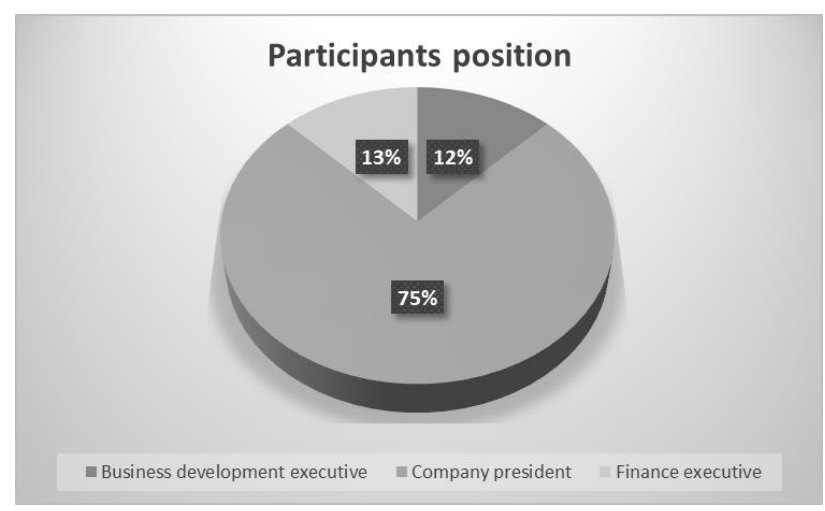

Source: Study Analysis

Figure 1. Participants' Position

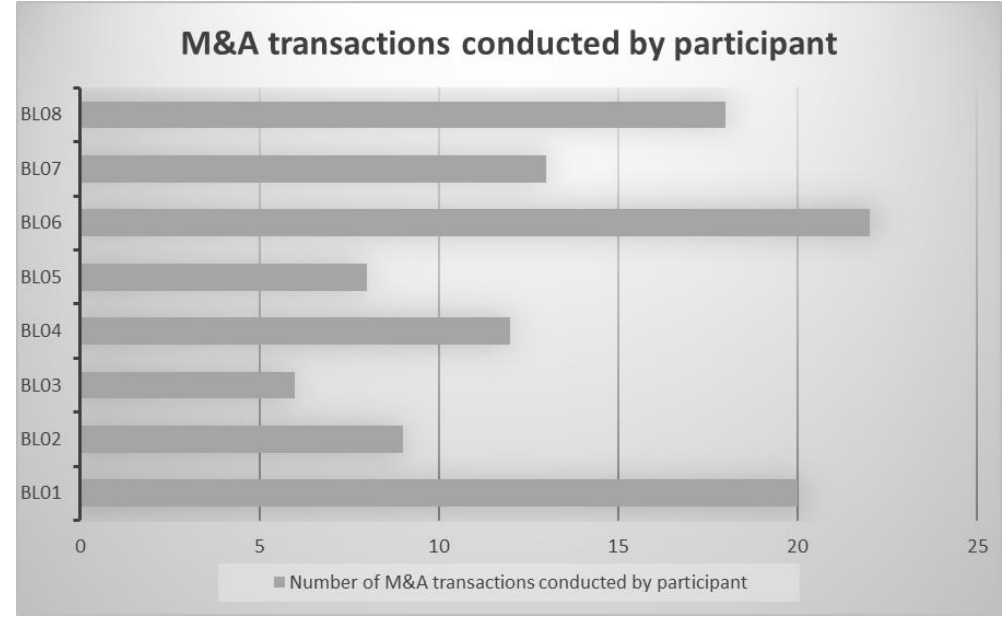

Source: Study Analysis

Figure 2. M\&A Transactions Conducted by Participants

processes were identified. Table 2 illustrates these categories and the percentage of participants that mentioned them during the interviews. The following emerging themes with the percentage of participants indicating it during the interviews were identified: (a) leadership focus with 29 percent, (b) value creation with 15 percent, (c) integration strategy with 14 percent, (d) the review process with 14 percent, (e) relationship development with 12 percent, and (f) organizational governance with 10 percent.

Other themes were also identified, but they had fewer occurrences. Upon assessing these themes, connections with the six primary themes were found, so they were combined with the primary six themes. The primary themes aligned with the literature review and the conceptual framework. 


\section{Ben Jacob}

\begin{tabular}{cc}
\hline Themes & $\begin{array}{c}\text { Percentage of } \\
\text { Participants }\end{array}$ \\
\hline Leadership focus & $29 \%$ \\
Value creation & $15 \%$ \\
Integration strategy & $14 \%$ \\
Review process & $14 \%$ \\
Developing relationship & $12 \%$ \\
Organizational governance & $10 \%$ \\
\hline Source: Author's Presentation
\end{tabular}

\section{Table 2. Emerging Themes with Percentage of Categorical Response}

Theme 1: Leadership Focus. The majority of business leaders are actively engaged with M\&A activity to pursue fast business growth (Sinclair and Keller, 2017). Leadership focus refers to the capability of an organization's leaders to articulate a defined roadmap and motivate others to achieve the desired goals. All participants mentioned the contribution of leadership focus on the success of M\&A. The count of leadership focus occurrences in the participants' replies was the highest. In addition to that, as illustrated in Figure 3, the leadership focus theme had a high percentage of reply occurrences between the participant. Participants BL05 and BL02 suggested that this theme has the most critical role in the success of M\&A with 46 percent and 38 percent, respectively.

The participants included the following activities and processes that they found to be related to this theme: active participation, strong commitment, enhanced collaboration, trust, and ownership. Participant BL05 expressed the importance of leadership focus on providing a clear business strategy and focus on the right company targets. According to Participant BL05, the alignment of the M\&A strategy with the overall business strategy enabled the commitment of the team and better clarity of the strategy. The outcome of this leadership direction was the definition of priorities to the organization, improved speed of decision-making, and the continuation of the M\&A model focus. According to BL05, "A key obstacle for us is the speed of decision making within our company corporation, and it slows us down. This is why it is important to have aligned and clear strategy so that when you ask for approval to pursue a deal, the corporation can easily sign off as it fits the aligned strategy". Participant BL02 shared another aspect of leadership focus in terms of enabling effective working relationships that enlarge the functions involved in the M\&A, internally and externally.

Theme 2: Value Creation. The participants described the value creation theme as a key strategy that they used in the process of M\&A. Figure 4 illustrates the percentage of reply occurrences between the participants to the value creation theme. Participants BL06 and BL04 suggested that this theme has the most critical role in the success of M\&A with 28 percent and 22 percent, respectively. 


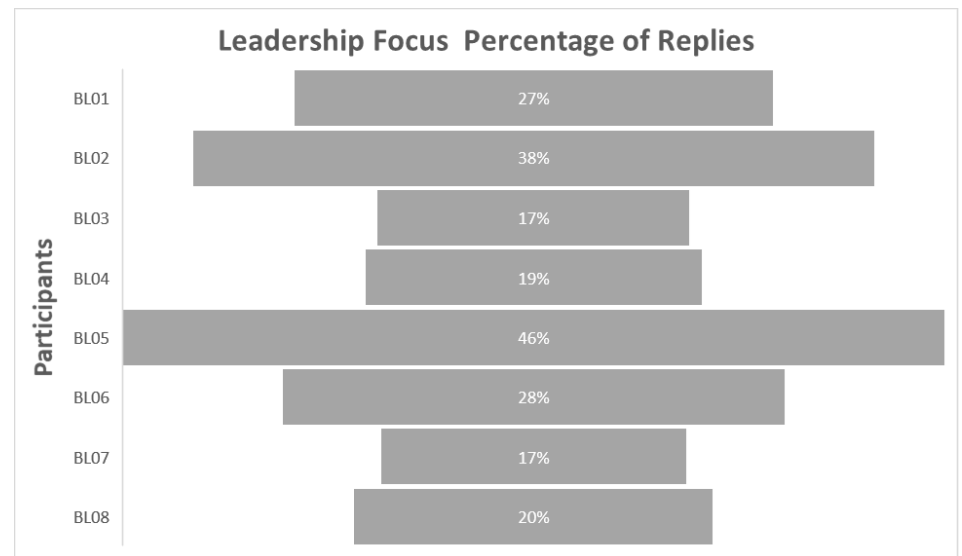

Source: Study Analysis

Figure 3. Leadership Focus Theme Percentage of Replies

Business leaders use the M\&A process to accelerate growth, to expand on valuable capabilities, to access assets that are costly to imitate, and to reduce competition (Brueller, Carmeli and Markman, 2018).

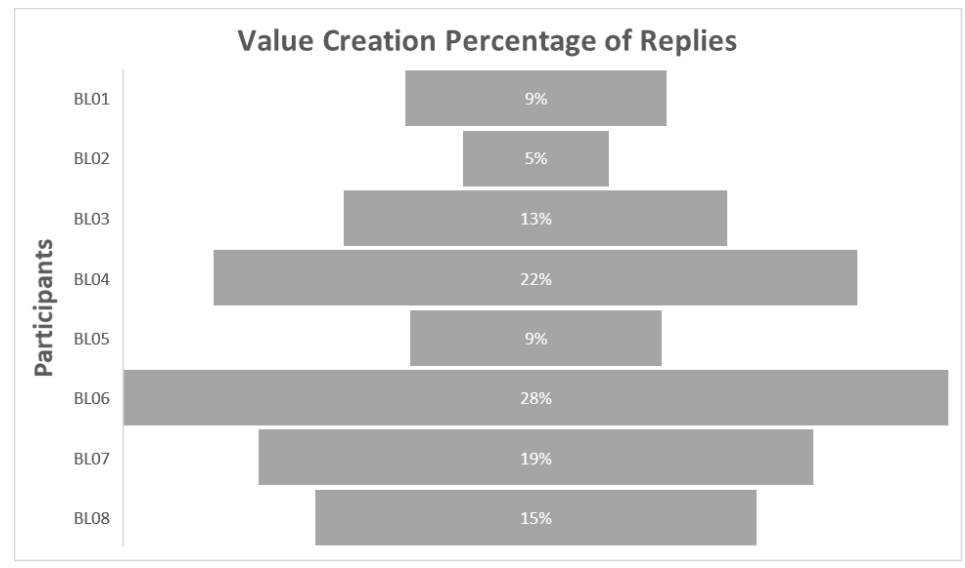

Source: Study Analysis

Figure 4. Value Creation Theme Percentage of Replies

The expected outcome of M\&A should be reflected in creating value for the organization. According to participant BL04, they planned the M\&A value creation in the following three aspects: what is needed for the company to enable growth, what are the market's needs, and the connection to the overall strategy of the company. According to BL04, "We look at what we need to enable the growth of 


\section{Ben Jacob}

our company and growth in the market that we are doing business. Also, we assess where are the markets that we want to be going forward and identifying assets that would essentially enable us to be opening doors to additional markets and segments that we consider important for us to be in the future".

The participants linked the value creation to the financial aspects such as enabler to the company's long-term financial planning strategic direction, improved revenue, and cost synergies and generating value to the acquired company.

Theme 3: Integration Strategy. The M\&A process of evaluating the target, along with the potential value creation, such as economic growth or improved innovation for the acquiring company, and continued progress until the completion of the M\&A transaction. The next phase after signing the agreement between the two companies, is the planning of the integration process of the two companies. As part of the integration process, the acquiring team is planning how to combine two separate companies that have different cultures, pace, processes, and other differences to collaborate in a defined time frame. All the participants highlighted the importance of integration planning and execution as a key contributor to the successful outcome of M\&A. Figure 5 illustrates the percentage of reply occurrences between the participants to the integration strategy theme.

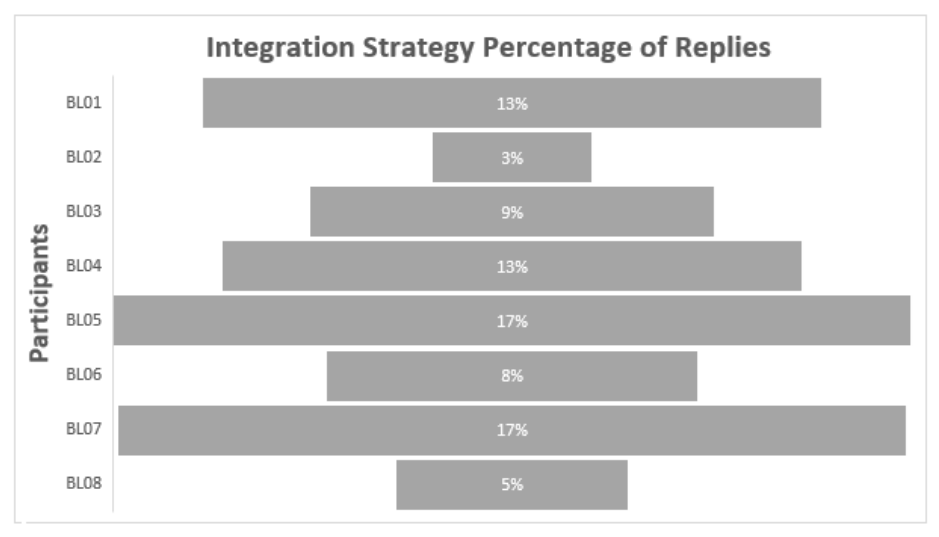

Source: Study Analysis

Figure 5. Integration Strategy Theme Percentage of Replies

According to BL08, the integration execution has a more significant influence on the success of M\&A than the strategies developed before the M\&A completion. Similar to BL08, other participants agreed on the importance of the integration strategy as an enabler step to allow the ability to scale the two companies faster, effective, and enable quick product launch. 
Theme 4: Review Process. The review process in the M\&A process is related to the process that the acquired company's core team is performing before they decide whether to progress with the acquisition or not. The participants referred to this process as due diligence that is conducted by a cross-functional team. During the due diligence process, each group from the company peer with the same group in the target company and assess the potential risks that may impact the decision to proceed with the M\&A or not. Some risks that the teams identify can be mitigated as part of the integration strategy that I mentioned above as theme 3. Figure 6 illustrates the percentage of reply occurrences between the participants to the review process theme.

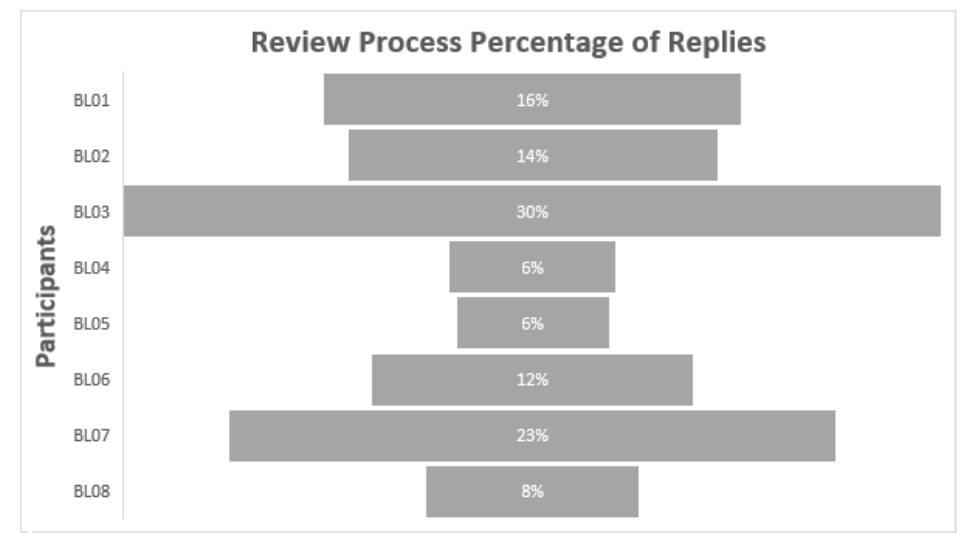

Source: Study Analysis

Figure 6. Review Process Theme Percentage of Replies

The participants discussed the importance of making the right decisions on which targets to acquire and eventually on the selected target. Participant BL01 said, "We are focusing our initial efforts on making the right decisions on the targets, which targets to acquire, and what value they can create. For that purpose, we are engaging the appropriate subject matter experts, both internal and external. We are often engaging customers and key opinion leaders as part of our acquisition assessment and due diligence".

The due diligence process was mentioned by other participants that highlighted "the importance of spending the needed time on the due diligence process and emphasized the need that this process will be executed in a detailed manner and by an experienced cross-functional team".

Theme 5: Relationship Development. Participants expressed the relationship development theme as a process that includes the need to get closer to the target company, to gain trust, and to follow a stepwise approach. The ability to create a relationship in the M\&A environment between two separate 


\section{Ben Jacob}

companies is difficult, and by collaboration and being open, the participants mentioned that it is possible. Figure 7 illustrates the percentage of reply occurrences between the participants to the relationship development theme.

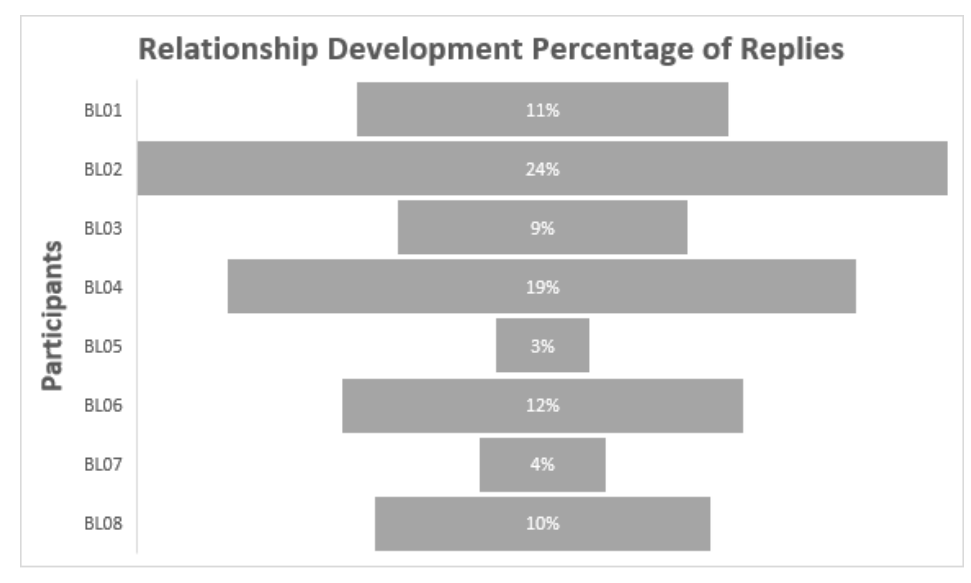

Source: Study Analysis

Figure 7. Relationship Development Theme Percentage of Replies

According to participant BL04, "You're going to smile with the term that I will be using, but you need to date before you get married. When you have a chance to get to know the organization before you acquire and fully integrate, it is definitely a plus". The action of creating a partnership between the two organizations helped to align the business needs and improve collaboration and accountability. Additionally, the involvement of senior leadership helped by driving the right resources to support activities and kept the M\&A project in the focus of reviewers.

Theme 6: Organizational Governance. All the participants mentioned the organizational governance process as a step that is part of the routine company processes that occurred in every transaction of M\&A. The participants said the periodical review cycle that each M\&A deal had once the acquisition executed. Figure 8 illustrates the percentage of reply occurrences between the participants to the organizational governance theme.

The participants mentioned the metrics that they held during those reviews and highlighted the comparison of the metrics with the deal model. BL03 said that the frequency of the reviews was monthly and that participation of leadership assured accountability of the team members. According to BL05, "We do a review within the management board along with the business development team, and we check how we are doing in the M\&A area. Also, there are deal retrospective reviews of how 


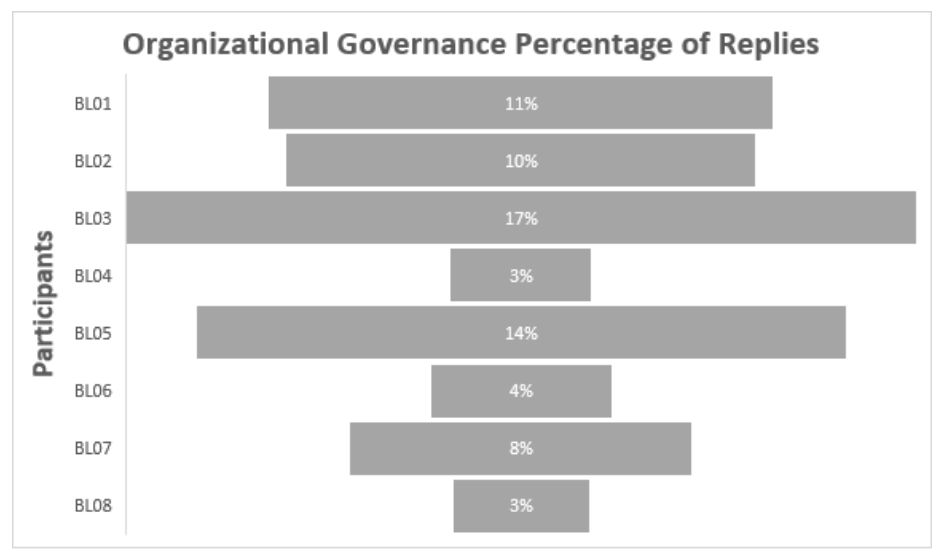

Source: Study Analysis

Figure 8. Organizational Governance Theme Percentage of Replies

effective we are in our strategy". The participants mentioned a structured process of periodical review and continual learning in the areas that the company did not meet the deal model and what the company leadership needed to execute to improve this. Additionally, BL01 mentioned that as part of the review process, it enabled the approval and alignment of leadership with elements of the deal and the needed next steps to address it.

Additional themes that participants mentioned that impact on the M\&A strategies were the following: Innovation and knowledge transfer, cultural (behavior of people in the acquired company), and communication. The participants highlighted the importance of having stable and high performing people and team members who worked on the M\&A process. The ability to maintain this team supported the flawless integration process and did not slow down the innovation process. The innovation and knowledge transfer theme is an input to the integration strategy, and business leaders should assess it as part of planning the integration process. The participants presented the cultural theme as one of the differences between the two companies. Participants mentioned that usually, the acquired companies had a startup culture, unlike the corporate culture that they referred to as slow and complicated. The cultural theme that participants mentioned aligned with the literature review, and was connected with the leadership focus theme as business leaders should address those cultural differences as part of their activities to enhance collaboration. Lastly, the participants referred to communication as an essential factor in enabling clear message, transparency, and open communication. BL02 suggested that constant communication and shared value with the target promoted to have a collaborative and transparent environment. The communication theme was connected with the review process theme and organizational governance, as those themes included 


\section{Ben Jacob}

the communication piece as part of the process.

\section{DISCUSSION}

The researchers who studied the M\&A process and outcomes listed multiple factors that contribute to the success of M\&A. The study results offered key elements that define successful, effective M\&A strategies that business leaders could deploy to increase the success rate of M\&A in their organization. The six themes that emerged from the data analysis should be considered as the main factors that contribute to M\&A outcomes.

There was an alignment of the themes that were identified as part of the interviews with current literature. Also, the themes aligned with the conceptual framework of effectuation theory. The effectuation theory was introduced as a tool for decision-making logic in entrepreneurship (Reymen et al., 2017). Entrepreneurs use the effectuation theory both in static and dynamic environments that require constant changes and adjustments (Sarasvathy et al., 2014).

One of the principles in the effectuation theory is the pilot in the plane. As part of the pilot in the plane principle, the effectual entrepreneurs do not see history running on autopilot without their influence, control, and focus. The effectual entrepreneurs consider themselves one of many who copilot the course of history (Sarasvathy et al., 2014). Similar to the pilot in the plane principle, the participants mentioned the leadership focus as a driver that led to successful M\&A. Business leaders drive growth by using their influence, control, and providing guidance and direction to their teams. According to the participants, leadership engagement and oversight helped in improving the awareness, accountability, trust, and commitment that was needed to succeed in executing the M\&A. The participants highlighted the importance of having alignment and clear strategy from leadership to drive successful results of M\&A. During the literature review, the role of leadership and its influence on M\&A was discussed. According to Daniliuc et al. (2014) leadership focus had a critical role and effect on the performance and financial results of the post-acquisition. In the study of Rodríguez-Sánchez, Ortiz-de-Urbina-Criado and Mora-Valentín (2019) the authors suggested that leadership was essential to the success of M\&A by facilitating, gaining trust, and developing of their employees. Bashan and Armon (2019) also mentioned the importance of leadership as a driver to develop strategies for continued improvement.

Another application of the pilot in the plane principle is reflected in the ability of leadership to influence and guide the process of identifying and selecting the target company to acquire. Leaders expect to get detailed information so that they can base their decision if to progress with M\&A activity. The anticipated outcome of M\&A should be reflected in creating value for the organization. As 
mentioned by participants, value creation was a factor that their company focused on assessing the applicability of M\&A deals in terms of fitting to their company's long-terms strategic goals. According to Gomes et al. (2013) M\&As are essential for companies to improve their strategies, financial outcomes, and social terms. Olcay, Öner and Olcay (2019) linked the M\&A expected results with better innovation and better financial performance.

The bird in hand principle in the effectuation theory discusses the need of entrepreneurs to collaborate and being engaged in social interactions (Sarasvathy et al., 2014). The ability of entrepreneurs to have this engagement should support the following three processes: identity (who I am), knowledge (what I know), and networks (whom I know). The benefit that entrepreneurs can get from this principle is in having a deeper understanding and insights on the M\&A deal by using all the knowledge and experience that they have from past transactions and partner with people who they know that can support them with this investigation activity. This principle relates to the process of the target company review process. During this review process, acquired companies conduct the due diligence process to the target company to make an informed business decision on whether to proceed with the acquisition (Patel, 2018). Researchers discussed the importance of the due diligence process as part of the common elements that make up every M\&A deal (Bhagwan et al., 2018). The importance of the review process of the target company and the integration process is essential for the success of M\&A. The participants discussed the integration strategy and highlighted the importance of planning the integration process and proper execution of it on the overall success of the M\&A process. The impact of creating an effective integration strategy on the success of M\&A was discussed by Gomes et al. (2013). The ability of leaders to get the relevant and available information was highlighted by the participants as a key to guide their decision making successfully both as part of the due diligence and integration processes.

The principle of the crazy quilt was another principle in the effectuation theory that was relevant to the relationship development theme. According to Sarasvathy et al. (2014), entrepreneurs drive partnerships as the central method to expand resources. According to this principle, entrepreneurs should rapidly engage in conversations with a variety of people who they already know or come into contact with as with some they will end up making actual commitments to the new venture (Sarasvathy et al., 2014). The participants expressed the relationship development theme as a process that included the need to get closer to the target company, to gain trust, and to follow a stepwise approach. In using the crazy quilt principle, leaders can expand their resources and drive better engagement. Also, the action of creating a partnership between the two organizations helped to align the business needs and improve collaboration and accountability. Additionally, the involvement of 


\section{Ben Jacob}

senior leadership helped by driving the right resources to support activities and kept the M\&A project in the focus of reviewers. The relationship creation was discussed in the literature review and the impact of it on the success of the M\&A process (Fine et al., 2016). Ahmed (2019) suggested the importance of working across interdisciplinary groups will ensure a high level of trust, reduce stress, strengthening relationships, and fostering of ownership. The study conducted by Rodríguez-Sánchez et al. (2019) presented the importance of having a strong leadership because of its direct and informal relationship with the lower-ranking personnel to soften the initial rejection and manage the transition stage.

The effectual theory principle of lemonade fitted to the organizational governance theme. According to Sarasvathy et al. (2014), entrepreneurs often operate in conditions of enhanced uncertainty, they may benefit from embracing surprises rather than following a linear and goal-oriented process that is designed to avoid deviations from the plan. In adopting the approach of leveraging uncertainty by treating surprises as opportunities, leaders can benefit from using a structured review process. By adding structured methodologies such as the review process, the uncertainties embedded in the M\&A process could be reduced. All the participants mentioned the organizational governance process as a step that is part of the routine company processes that occurred in every transaction of M\&A. The governance review process enhances the ability to control and monitor the decision making of entrepreneurs and enables the success of the M\&A process.

The findings of this study may aid business leaders in developing the key strategies that may help them to conduct a successful process of M\&A. Also, it may improve the outcome of the M\&A in their companies.

\section{IMPLICATIONS}

M\&A is a key process that business leaders use to grow their business. Business leaders who use M\&A have the opportunity to develop new markets or to seek the transfer of technology and innovation to keep pace with the globalization of business (Bauer et al., 2016). The majority of M\&As fail to deliver the expected value to the acquirers ( $\mathrm{Du}$ and Jaw, 2018). M\&A process is conducted with multiple uncertainties. To deal with these uncertainties the effectuation theory provides a valuable conceptual framework suggesting few principles to help business leaders to cope with these unknown situations. This study explored the strategies that business leaders used to conduct successful M\&A. The strategies that the participants shared were aligned with the literature sources and provided areas of focus to enable an improved M\&A process.

The study findings include six themes that business leaders used to conduct successful M\&A processes: (a) leadership focus, (b) value creation, (c) integration strategy, (d) the review process, (e) 
relationship development, and (f) organizational governance. The combination of the participant's insights, the literature resources, and the effectuation theory can guide business leaders to base their decision and develop their M\&A strategies. Business leaders who will follow the identified themes will be able to improve outcomes of M\&A by better planning and by creating an effective strategy that will enable collaboration, trust, and transparency. Also, if the business leaders focus their efforts on developing an integration strategy that will be based on open communication with the acquired company along with a periodic review process, they can improve the M\&A outcomes. Following their experience, the participants suggested tools that they used to conduct successful M\&A. The ability to use those tools may bring to a better success rate of M\&A that will support financial and technological growth. The findings of this study may assist business leaders' needs as they plan to conduct M\&A to allow better planning and success.

\section{LIMITATIONS AND FUTURE DIRECTIONS}

The purpose of this qualitative single-case study was to identify and explore business leaders' strategies to conduct successful M\&A processes. Applying methodological triangulation and data analysis, six themes that business leaders used to perform successful M\&A processes were identified: (a) leadership focus, (b) value creation, (c) integration strategy, (d) the review process, (e) relationship development, and (f) organizational governance.

The study had two limitations, the first limitation is relying on a small sample of business leaders from a global healthcare company that has been successful in executing M\&As for their knowledge, lessons learned, and experience. Further research inquiries could explore similar study with a larger sample of business leaders. Also, future researchers may explore industries other that the healthcare industry and compare strategies found in this study and the other industries. Lastly, future researchers can assess strategies that business leaders used for unsuccessful M\&A and use them as an opportunity to identify new approaches that can be used differently and trigger successful outcomes.

The second limitation was the potential unavailability of the interview participants as they are considered senior leadership in the company, and their time is limited. While this concern proved to be not applicable and all participants were available to participate, other researchers could adopt a larger sample size and extend the research method to multiple-case studies to gain more inputs from other organizations. The ability to enlarge the sample size of participants may lead to the opportunity to get more information and strategies that can be used to guide business leaders when they plan their future $M \& A$.

\section{RECOMMENDATIONS}




\section{Ben Jacob}

Strategies that business leaders used to conduct successful M\&A were identified in this study. Further inquiry is needed to expand this strategy recommendation used successfully during M\&A on a broader global level. Researchers can use the same interview questions and apply them to a bigger sample size of participants with a worldwide footprint. The exploring of the themes globally will allow a more in-depth evaluation of the factors that business leaders used to conduct successful M\&A. As the strategies are dependent on several factors, this additional evaluation broadly may suggest more tools to improve the outcome of M\&A.

Other researchers are recommended to conduct the study in various industries to compare the identified themes. The expansion of this research to more sectors outside the medical device industry may bring to the identification of more themes that may apply to a specific sector. As each industry has unique requirements and activities, this assessment may result in either introduction more themes or validating existing themes. The integration of the themes identified in this study, along with new themes, will allow M\&A researchers to suggest robust factors that business leaders can use when planning their next M\&A deals.

\section{REFERENCES}

Ahmed, I. (2019). Staff well-being in high-risk operating room environment: Definition, facilitators, stressors, leadership, and team-working - A case-study from a large teaching hospital. International Journal of Healthcare Management, 12(1): 1-17. https://doi.org/10.1080/20479700.2017.1298228

Bari, M. W., Fanchen, M. \& Baloch, M. A. (2016). Management practices and performance of mergers and acquisitions in Pakistan: Mediating role of psychological contract. SpringerPlus, 5(1): 1-16. https://doi.org/10.1186/s40064-016-3184-3

Bashan, A. \& Armon, D. (2019). Quality management challenges in a dynamic reality of mergers, acquisitions and global expansion. International Journal of Quality and Reliability Management, 36(7): 1192- 1211. https://doi.org/10.1108/IJQRM06-2018-0161

Bauer, F., Matzler, K. \& Wolf, S. (2016). M\&A and innovation: The role of integration and cultural differences-A central European targets perspective. International Business Review, 25(Part A): 76-86. https://doi.org/10.1016/j.ibusrev.2014.07.010

Ben Jacob, A. (2020). Leadership Strategies for Improving Mergers and Acquisitions Performance. Walden Dissertations and Doctoral Studies. No: 7913.

https://scholarworks.waldenu.edu/dissertations/7913

Bhagwan, V., Grobbelaar, S. S. \& Bam, W. G. (2018). A systematic review of the due diligence stage of mergers and acquisitions: Towards a conceptual framework. South African Journal of Industrial Engineering, 29(3): $217-234$. https://doi.org/10.7166/29-3-2061

Brueller, N. N., Carmeli, A. \& Markman, G. D. (2018). Linking merger and acquisition strategies to post merger integration: A configurational perspective of human resource management. Journal of Management, 44(5): 1793-1818. https://doi.org/10.1177/0149206315626270

Daniliuc, S., Bilson, C. \& Shailer, G. (2014). The interaction of post-acquisition integration and acquisition focus in relation to long-run performance. International Review of Finance, 14(4): 587-612. https://doi.org/10.1111/irfi.12040

Du, K. \& Jaw, Y.M. (2018). Pacing international acquisitions: Emerging markets as the new success stories. Journal of Business Strategy, 39(4): 3-10. https://doi.org/10.1108/JBS-05-2017-0072

Eckardt, R. \& Skaggs, B. C. (2018). Service diversification and growth of professional service firms. Long Range Planning, 51(1): 111-126. https://doi.org/10.1016/j.Irp.2017.06.003

El Zuhairy, H. (2015). Postmergers and acquisitions: The motives, success factors and key success indicators. Eurasian Journal of Business and Management, 3(2): 1-11. https://doi.org/10.15604/ejbm.2015.03.02.001

Farhan, A., Aneeta, M. \& Shafique, A. (2018). Merger \& acquisition strategy for growth, improved performance, and survival in the financial sector. Journal Perspektif Pembiayaan Dan Pembangunan Daerah, 5(4): 196-214. https://doi.org/10.22437/ppd.v5i4.5010

Feng, X. (2016). Research on the relationship among M\&A behavior, investment efficiency and firm value: Empirical evidence 
from A shares of listed corporations. Technology and Investment, 7(2): 27-32. http://dx.doi.org/10.4236/ti.2016.72004

Fine, M., Gleason, K. \& Budeva, D. (2016). Getting what you're worth: Implications that affect firm value in a brand acquisition. Journal of Brand Management, 23(5): 70-96. https://doi.org/10.1057/s41262-016-0006-4

Friedman, Y., Carmeli, A., Tishler, A. \& Shimizu, K. (2016). Untangling micro-behavioral sources of failure in mergers and acquisitions: A theoretical integration and extension. International Journal of Human Resource Management, 27(20): 23392369. https://doi.org/10.1080/09585192.2015.1042003

Gomes, E., Angwin, D. N., Weber, Y. \& Tarba, S. Y. (2013). Critical success factors through the mergers and acquisitions process: Revealing pre- and post-M\&A connections for improved performance. Thunderbird International Business Review, 55(1): 13. https://doi.org/10.1002/tie.21521

Haeruddin, M. I. M. (2017). Mergers and acquisitions: Quo vadis? Scientific and Academic Publishing, 7(2): 84-88.

Hongjiu, L., Qingyang, L. \& Yanrong, H. (2019). Evaluating risks of mergers \& acquisitions by grey relational analysis based on interval-valued intuitionistic fuzzy information. Mathematical Problems in Engineering, $201(9)$ : 1-7. https://doi.org/10.1155/2019/3728029

Jisr, R. E. \& Maamari, B. E. (2017). Effectuation: Exploring a third dimension to tacit knowledge. Knowledge and Process Management, 24(1): 72-78. https://doi.org/10.1002/kpm.1536

Junni, P., Sarala, R. M., Tarba, S. Y. \& Weber, Y. (2015). The role of strategic agility in acquisitions. British Journal of Management, 26(4): 596-616. https://doi.org/10.1111/1467-8551.12115

Kar, R. N. \& Kar, M. (2017). Cross-cultural issues in M\&As: Experiences and future agenda from Asia-Pacific deals. Transnational Corporations Review / Kuaguo Gongsi, 9(3): 140-149. https://doi.org/10.1080/19186444.2017.1362861

Karagiozis, N. (2018). The Complexities of the researcher's role in qualitative research: The power of reflexivity. International Journal of Interdisciplinary Educational Studies, 13(1): 19-31. https://doi.org/10.18848/2327-011X/CGP/v13i01/19-31

Lewis, S. (2015). Qualitative inquiry and research design: Choosing among five approaches. Health Promotion Practice, 16(4): 473-475. https://doi.org/10.1177/1524839915580941

Loukianova, A., Nikulin, E. \& Vedernikov, A. (2017). Valuing synergies in strategic mergers and acquisitions using the real options approach. Investment Management and Financial Innovations, 14(1): $236-247$. http://dx.doi.org/10.21511/imfi.14(1-1).2017.10

Lub, V. (2015). Validity in qualitative evaluation: Linking purposes, paradigms, and perspectives. International Journal of Qualitative Methods, 8(5): 1-14. https://doi.org/10.1177/1609406915621406

Nandi, S. \& Nandi, M. L. (2017). Revisiting activity theory: A useful framework for improving post-acquisition integration effectiveness. Vilakshan: The XIMB Journal of Management, 14(1): 1-18.

Olcay, G. A., Öner, M. A. \& Olcay, A. B. (2019). A conceptual view of exergy destruction in mergers and acquisitions. Technological Forecasting and Social Change, 143, 336-352. https://doi.org/10.1016/j.techfore.2018.06.008

Patel, A. (2018). Exploring traditional due diligence processes in South Africa. Journal of Economic and Financial Sciences, 11(1): 1-10. https://doi.org/10.4102/jef.v11i1.180

Reymen, I., Berends, H., Oudehand, R. \& Stultiens, R. (2017). Decision making for business model development: A process study of effectuation and causation in new technology-based ventures. $R$ and $D$ Management, 47(4): 595-606. https://doi.org/10.1111/radm.12249

Rodríguez-Sánchez, J.-L., Ortiz-de-Urbina-Criado, M. \& Mora-Valentín, E.-M. (2019). Thinking about people in mergers and acquisitions processes. International Journal of Manpower, 40(4): 643-657. https://doi.org/10.1108/IJM-05-2018-0143

Rottig, D., Schappert, J. \& Starkman, E. (2017). Successfully managing the sociocultural integration process in international acquisitions: A qualitative analysis of Canon's acquisition of Océ. Thunderbird International Business Review, 59(2): 187208. https://doi.org/10.1002/tie.21831

Sarasvathy, S., Kumar, K., York, J. G. \& Bhagavatula, S. (2014). An effectual approach to international entrepreneurship: overlaps, challenges, and provocative possibilities. Entrepreneurship: Theory and Practice, 38(1): 71-93. https://doi.org/10.1111/etap.12088

Sarasvathy, S. D. (2001). Causation and effectuation: Toward a theoretical shift from economic inevitability to entrepreneurial contingency. Academy of Management Review, 26(2): 243-263. https://www.jstor.org/stable/259121

Sarasvathy, S. D. \& Dew, N. (2005). Entrepreneurial logics for a technology of foolishness. Scandinavian Journal of Management, 21(4): 385-406. https://doi.org/10.1016/j.scaman.2005.09.009

Sinclair, R. \& Keller, K. L. (2017). Brand value, accounting standards, and mergers and acquisitions: "The Moribund Effect". Journal of Brand Management, 24(2): 178-192. https://doi.org/10.1057/s41262-016-0025-1

Yang, M. \& Gabrielsson, P. (2018). The interface of internationall marketing and entrepreneurship research: Review, synthesis, and future directions. Journal of International Marketing, 26(4): 18-37. https://doi.org/10.1177/1069031X18809988

Yin, R. K. (2015). Qualitative research from start to finish (2nd ed.). New York, NY: The Guilford Press.

Yin, R. K. (2018). Case study research and applications: Design and methods (6th ed.). Thousand Oaks, CA: Sage. 


\section{Ben Jacob}

Appendix-1

\section{Interview Questions}

The following research questions were used in the exploration, explanation, description, and identification of the strategies that business leaders used to conduct successful M\&A in the medical device sector.

1. What strategies have you used to conduct successful M\&As?

2. What processes did you develop and implement for formulating the M\&As strategies that you used?

3. Please share your organization's vital few learnings that may have influenced, informed, and otherwise shaped the M\&As strategy.

4. What key obstacles did your organization encounter regarding the strategies used to conduct successful M\&As?

5. How did your organization address the key obstacles to implementing the successful strategies for M\&As?

6. How did your organization assess the effectiveness of its strategies for improving the success of its M\&A processes to improve the outcome of the M\&As?

7. What else would you like to share that we did not address about your organization's strategies and processes for developing and implementing successful M\&As? 